\title{
The Appropriate Extent of Intellectual Property Rights in Art*
}

\author{
ALAN V. DEARDORFF \\ Department of Economics, University of Michigan, Ann Arbor, MI 48109-1220, U.S.A.
}

\begin{abstract}
The paper examines whether intellectual property rights in art should be extended to the entire world. In earlier papers, the economics of patent rights have been examined and the argument made that world welfare is likely to fall if patent rights are extended to the entire world. This argument is recapitulated here with special attention to the assumptions that are needed for its validity. These assumptions are then reexamined in the context of markets for art to see whether the argument carries over. It is found that while most of the assumptions do carry over well enough to justify the argument, there are also certain circumstances that may require greater geographic extension of intellectual property rights in some cases.
\end{abstract}

Key words: Intellectual property, economics of the arts

\section{Introduction}

In two papers, Deardorff $(1990,1992)$, I have questioned the desirability of extending intellectual property (IP) rights to countries that currently do not have them. I have argued, in the case of patents and under certain assumptions, that such extension is harmful to the countries where the new rights are introduced. More important, I show that extension of IP rights to all countries of the world reduces world welfare, in that these countries lose more than is gained by the other countries whose IP rights are being extended. Finally, I suggest that the least developed countries ought therefore to be exempted from the provisions that have been negotiated in the Uruguay Round of the GATT to extend IP rights to all countries of the world. In this paper I examine whether these arguments are applicable to another area of IP protection: art.

I will not undertake a formal analysis here. That could be obtained directly from Deardorff (1992) by simply changing the names and repeating the same equations and diagrams. Rather, the question is whether the assumptions of that analysis are as appropriate to artistic creations as they are to inventions subject to patents. If so, then the argument of that paper carries over to art; if not, then the changed assumptions may be suggestive of what alternative conclusions might be appropriate.

\footnotetext{
* Paper prepared for a conference on 'The Economics of Intellectual Property Rights', International Center for Art Economics, University of Venice, October 6-8, 1994.
} 
In Section 2 of the paper I will review the argument from the previous papers, paying particular attention to the critical assumptions that were made and the roles that they play. In Section 3, I will speculate on how these critical assumptions may or may not match the reality of the world of art. Finally, in Section 4, I consider two additional characteristics of art that may also raise questions about the appropriateness of the kind of economic analysis that provides the basis for the rest of the paper.

\section{The Argument for Geographically Limited Intellectual Property Protection}

I begin by reviewing the argument for geographically limited IP protection in the case of patents. The framework is one in which certain economic agents devote their efforts and resources to inventing new products or processes. Once invented, at whatever cost, the processes can be used and the products produced repeatedly at some other cost, and other economic agents derive benefits from that production.

Patents protect such inventions by granting the patent holder the exclusive right, within the jurisdiction of the patent, to produce the product (or use the process) and to license that production to others. As a result, the patent holder acquires the ability to act as a monopolist in the market for the product, charging a monopoly price and earning monopoly profit. The economic rationale for having patents rights at all is that this monopoly profit provides a return to inventive activity, without which many products that could be socially beneficial would not be invented. My argument for limited IP protection accepts this rationale, even though it acts in the direction of justifying more IP protection, not less. Thus the first assumption is that invention is responsive to profit, or more generally,

ASSUMPTION 1. The creation of intellectual property is responsive to the financial incentive for creating it.

A patent is a very imperfect means of providing this incentive, however. On the one hand, for reasons familir from basic economic theory, it causes the consumer of the invented product to pay a monopoly price, higher than the marginal cost of producing the product, and therefore causes less of the product to be consumed than would be optimal. This is the standard 'dead weight loss' from monopoly pricing, and it will be positive whenever consumer demand responds at all to price. Thus we have

ASSUMPTION 2. Consumer demand for the products of intellectual property is responsive to price.

This means that even if a socially optimal number of inventions were created, their benefit to society would be suboptimal under a patent since consumers would be discouraged from consuming them by a price in excess of marginal cost. 
On the other hand, while a patent causes a price that is too high from the standpoint of inducing optimal consumption, the monopoly price is also too low to induce an optimal amount of invention. For unless the patent holder can perfectly discriminate among demanders, charging a different price for each unit that is sold, there will be some units of the good sold at a price less than the benefit they create for consumers. The presence of this consumer surplus is beneficial to the consumers, but it also means that the monopoly profits are less than the total benefit of the invented good to society. Suppose that we think of the number of inventions as variable, with a whole spectrum of potential inventions existing that offer different costs and benefits to society. Then this fact - that patent holders, even with their monopolies over the market, do not secure for themselves the full social benefits from their innovations - will mean that some inventions whose social benefits would have exceeded their social costs will not be invented. Thus this conclusion that invention is suboptimal under a patent is based on two additional assumptions:

ASSUMPTION 3. Holders of intellectual property rights cannot engage in perfect price discrimination.

ASSUMPTION 4. There exists a wide range of potential intellectual property creations yielding a wide range of potential benefits to society.

These assumptions together imply that, for a single country or jurisdiction, a system of patents to protect inventions will be desirable but not optimal. It is desirable, because without it nothing at all will be invented (assumption 1) and all social benefits will be lost. It is not optimal, however, for the reasons just described, since too little invention will take place and at the same time too little will be consumed of those products that are invented. Optimality in both dimensions would require that inventors somehow be given an incentive, at the margin, that is equal to the full social benefit from what they invent, and at the same time that consumers be charged prices equal only to the marginal cost of producing an additional unit of the good once it is invented, and not including the cost of invention itself. It is possible to imagine a system of subsidies to invention, together with perfect competition in production, that might have these properties, but in practice it would never be possible to get the subsidies right. Therefore a patent system is a very useful second best mechanism.

Now suppose that there are multiple jurisdictions, which I will call countries, though the argument does not require that. One could imagine circumstances in which it would be impossible or meaningless to have patents in one country but not another. Suppose there were no monitoring of borders, for example, and no transport costs, so that sellers from one country could sell freely in another. Then the granting of patent rights within only one country would confer no monopoly, since the patent holders would always be undercut by foreign competitors in all markets. In this case, the only meaningful alternatives are global patent protection or none at all, and as already noted the former clearly dominates the latter. Thus 
to have an argument for limited patent protection I must have some separation of national markets:

ASSUMPTION 5. Separate national intellectual property regimes are possible, in that the products of intellectual property can be kept out of a country if they do not conform to its rules regarding intellectual property rights.

On the other hand, if intellectual property itself (the information, not the goods produced with that information) does not cross national borders readily, then the issue of extending IP rights may again reduce to a trivial choice between all or nothing. That is, suppose that it were impossible to copy an inventionfrom another country. Then countries without patent protection would either have no access to the invented products at all, or they would have to buy from the foreign patent holders even though they honor no patents themselves, because only the foreign patent holders would have the necessary know-how. Therefore, the issue of limited patent protection becomes interesting only if such information does diffuse readily, which I assume:

ASSUMPTION 6. Once created, intellectual property is technologically capable of being exploited freely throughout the world.

Under these assumptions, if patent protection is provided in only one part of the world, then patent holders will charge monopoly prices and earn monopoly profits only within the countries that enforce that protection, while consumers in the rest of the world will have access to patented products at marginal cost from competitive suppliers. In that situation the extension of patent protection to a country that did not previously provide it does not give that country's consumers access to previously patented products, since they already had that access. Instead, there are three effects that arise from extending protection to a new country, one a transfer and the other two involving efficiency:

1. A transfer from the new country's consumers to the holders of existing patents, as prices rise to monopoly levels for existing patented products that these consumers continue to buy.

2. An efficiency loss borne by the new country's consumers as they reduce consumption of existing patented products when their prices rise.

3. An efficiency gain to consumers in all countries as the increased profit to be had from any invention induces some previously unprofitable inventions to be undertaken.

Note that effects 1 and 2 are both losses for the new country, with only effect 3 being a gain, except to the extent that some holders of existing patents are residents of the new country. In my earlier work I have excluded that possibility, though that is not necessarily the case. 
ASSUMPTION 7. Intellectual property rights are granted primarily to residents of the countries that implement intellectual property right regimes.

This assumption matters only for the distributional consequences of an extension of IP rights, not for effects on world welfare. Under this assumption, the three effects above assure that extension of IP rights to a new country that is small compared to the part of the world already covered will lower the welfare of the new country.

Similarly, the countries that start out with IP protection stand only to gain from its extension to other countries, since effects 1 and 3 above are beneficial to them, while effect 2 does not matter for them. Therefore, it is not surprising that early discussions of IP issues under the GATT were initiated by the developed countries that already had IP protection and were resisted by the developing countries that did not. The most obvious effects on these countries were for the former to gain and the latter to lose.

To determine the effects on the world as a whole, one can ignore the transfer effect above and just compare the two opposing efficiency effects, 2 and 3 . Extension of IP protection to new countries will be beneficial for the world as a whole if effect 3 is larger than effect 2; it will be harmful if not. This comparison in turn depends on the number of previously invented products whose prices will rise with IP extension in effect 2, versus the number of new inventions that can be stimulted by IP extension in effect 3 . The latter could surely be larger than the former if the initial scope of IP protection were very small, so that few or no existing inventions would have been present. In that case, extension of IP rights to more countries would be desirable. But if initial IP protection already covers enough of the world to foster a large number of inventions, and if there is nothing special about the new country in terms of fostering new inventions, then the loss in effect 2 will be larger than the gain in effect 3 and the world will lose from IP extension.

ASSUMPTION 8. Demands for the products of intellectual property are the same in all countries, depending identically in all countries on prices and incomes.

The argument for stopping short of covering the whole world with patent protection is then as follows: As more and more countries are covered by patent systems, the number of existing patents grows and the efficiency loss from moving to monopoly pricing for the products of those patents in an additional country also grows. At the same time, inventors move further and further down the list of socially beneficial potential inventions as they get a larger share of the surplus, and the inventions that remain that could be induced by extension to an additional country are less desirable. These two effects together imply, for any but the most extreme configurations of the world, that at some point it becomes undesirable to extend IP protection still further. All of this is worked out more formally in Deardorff (1992) for linear functions relating demands to prices and the surplus from inventions to their costs. However, the logic of the argument is more general than that linear case and depends, as I have shown here, primarily on the assumptions listed above. 


\section{The Assumptions Applied to Art}

The world of art is large and diverse and I can not hope to capture it all here. Instead, I will pose a simple characterization of what the economics of art may entail and compare that against the assumptions list above. I leave a more informed analysis of particular types of art to others who might, if they are so inclined, structure their analysis too around these assumptions.

For IP rights to be an issue for art, the artistic creation must be more than just a single non-reproducible object or event. If paintings could not be copied, for example, then only one person at a time could possess a painting and ownership of the artistic creation would be the same as ownership of the object itself. The artist could retain control of his or her creation or pass that control to another by selling the painting.

A key feature of art for the present purpose is therefore the fact that it can be reproduced in some fashion. In many cases the reproduction may be imperfect and, therefore, less valuable than the original, but even a very imperfect copy can undermine the value of the original for the artist. And quite often, it is the copies, not the original, that are the normal mode of delivery. In music, for example, the original artistic creation may have been the studio-recording session or the electronically edited master tape, but it is the multiple copies of this, in the form of records, tapes, or compact discs, that deliver the creation to its audience. In the case of a painting, the original plays a more important role, of course, but prints made from the painting are also important modes of delivery. In these and other cases, because it is technologically possible to make a copy that has artistic value, it is equally possible for unauthorized copies to be made and to undermine the market for the original and for the legitimate copies.

My characterization of art for the purpose of this paper is therefore something that is first created, then copied, with only the copies being sold on the market. The creation itself uses resources, including materials and the time of the artist. Copies also use resources, but much less per copy than the original creation, and do not require the time of the artist. On the supply side, therefore, art is very similar to inventions, suggesting that exploring the parallel between the two is not misguided.

On the demand side, my discussion of patents said very little, except that products of inventions were subject to downward-sloping demand. That seems a harmless starting point for the (copied) art objects considered here, although I will speculate below on how special features of demand for art might enter the story.

I turn now to a discussion of each of the assumptions from Section 2. I will ask whether any modifications of them might be appropriate in considering IP for art and, of so, whether these modifications might alter the conclusion that IP protection should be geographically limited. 
ASSUMPTION 1. The creation of intellectual property is responsive to the financial incentive for creating it.

Do artists respond to money? The conception of the 'starving artist' suggests that they do not, and that artists are driven to create by some inner creative force that they cannot resist. If that were really true, then there might be no economic argument for IP protection of art at all, since it wouldn't be needed. My argument that IP protection should be geographically limited would not be needed, since there would be no protection to limit.

However, the starving artists aside, it seems clear that across the broad spectrum of artistic endeavor, a great many artists do respond to financial incentives, even if money provides only one of several motives for them to create. Even the starving artists will in fact respond to financial incentives, whether they wish to or not, if they starve to death and can no longer produce. Furthermore, most art requires some materials in addition to the artist's time, and financial constraints may limit the quantity and quality of an artist's creations.

On the other hand, it is probably true for at least some forms of art that much would be produced even if the artists earned nothing at all. They would have to support themselves doing other things, and they could not therefore produce as much as they would otherwise, but there would be some minimal amount of art that would exist even without IP protection of any kind. If so, this matters for my argument of limiting IP protection by making it stronger. Assuming that there are diminishing social returns to art, like everything else, then the more art we would have without IP protection, the larger will be the effect 2 that was discussed above, and the smaller will be effect 3 . The optimal extent of IP protection in art will therefore be reduced.

ASSUMPTION 2. Consumer demand for the products of intellectual property is responsive to price.

Downward sloping demand is such a pervasive assumption in economics that it may be unnecessary to question it here. Surely for most artistic creations it is valid, and we can move on. However, it does appear to some of us outside the art world that some art is purchased because of its high price, not in spite of it. To the extent that art lovers derive satisfaction in part from the high prices of the art that they own, either because of the status this confers or because of speculative expectations, artists could face a demand that rises with price, at least over some range.

Such upward sloping demand would invalidate the conventional market analysis that underlies the argument of this paper. In particular, the main motivation for limiting IP protection, which was the losses to consumers from paying monopoly prices, would disappear if these prices raised the welfare of those who paid them. This possibility, if it were true in the world of art, could turn my analysis on its head. However, I do not believe that it is a valid concern for most art. 
ASSUMPTION 3. Holders of intellectual property rights cannot engage in perfect price discrimination.

If artists could charge every buyer a different price, then they could extract all of the surplus that their work generated, and they would be motivated to create an amount of art that would be optimal. Further, since they would then be willing even with IP protection to charge the marginal buyer marginal cost, there would also be no distortion of consumer demand for art. Under these circumstances, world-wide IP protection of art would be efficient. One might still want to limit it for distributional reasons - the artists and the countries in which they live would now get all of the benefits from artistic creation - but this seems much less of a concern here than for inventions.

But while price discrimination may be feasible for non-reproducible art (you can charge what the market will bear for every painting, for example), it is surely not possible for the copies that are of concern here. The amount of price discrimination that is possible, through alternative packaging and labelling for example, is very limited.

ASSUMPTION 4. There exists a wide range of potenital intellectual property creations yielding a wide range of potential benefits to society.

The importance of this assumption for art is that it assures that there will exist some artistic creations that are not produced under the current level of IP protection that will be produced if protection is extended. If all possible art were far from the margin, all existing art being viable even with a lower return and all non-existing art remaining unviable even with a higher return, then the only efficiency gain to extending IP protection would disappear. It would be optimal to reduce IP protection, and thus increase consumer welfare, until one reached the point where price would matter after all for supply.

This may in fact be plausible for some types of art where the talent to produce it is very scarce and very distinct. If humanity only gives birth to a small handful of individuals who could possibly perform as opera tenors, for example, and if these are so scarce that they are fully employed at well above their opportunity cost, then a reduction in the scope for IP protection of their music would not cause them to sing any less and would give more of the world access to their performances.

However, this is an extreme example that is probably not valid even for tenors, and in most artistic endeavors there does seem to be a wide range of talents available.

ASSUMPTION 5. Separate national intellectual property regimes are possible, in that the products of intellectual property can be kept out of a country if they do not conform to its rules regarding intellectual property rights.

This assumption is obvously not entirely valid for all forms of art. Anyone who 
has purchased a pirated compact disc in another country and smuggled it home in their luggage can testify to the porousness of our borders. If this sort of arbitrage worked perfectly, then any system of IP protection in art that encompassed less than the whole world would provide no protection at all.

However, such arbitrage does not work perfectly, as is evidenced by the tremendous price differences that continue to exist between countries with and without IP protection. Thus, while the case of the smuggled CD indicates that borders are porous, the well-known price differences that motivate that smuggling indicate that sufficient barriers do exist for my argument to go through. As long as such price differences exist, then so will the efficiency loss of extending IP protection as described above.

ASSUMPTION 6. Once created, intellectual property is technologically capable of being exploited freely throughout the world.

As already discussed, it is only art that is or can be copied that poses problems of intellectual property protection. One could imagine, however, that for certain kinds of art the technology of copying might be confined to the country where the art originated, or that potential foreign copiers might be unable to gain access to the original. In such a case, without extension of IP protection, this art would be completely unavailable to foreign consumers and extending IP protection could only make them better off. Thus this assumption really is critical to the case for geographic limitation.

However, while I can imagine forms of art for which this would be true, I am not aware of any actual examples of it. Certainly, most of the art for which IP protection is discussed does satisfy assumption 6 , and one would be surprised, in view of the rapid international diffusion of technology, if that were not the case.

ASSUMPTION 7. Intellectual property rights are granted primarily to residents of the countries that implement intellectual property right regimes.

Extension of IP protection in art causes a transfer from consumers of previously unprotected art to those who possess the property rights. These beneficiaries are presumably, in most cases, the artists. If these artists are located in the country where IP protection previously was enforced, then as stated in effect 1 above, this transfer is from countries without IP protection to countries with IP protection. However, regimes of IP protection typically grant it to whomever the regime determines to be the rightful owner of the property, regardless of nationality. Suppose, for example, that Taiwan did not protect rights to music but that a Taiwanese recording artist were to become popular on the world market. The artist would undoubtedly secure rights to his or her music in the U.S., Europe, etc., even though protection would be unavailable in Taiwan. In that case, the extension of IP protection to Taiwan would cause a transfer from Taiwanese consumers to the Taiwanese artist, and a portion of effect 1 would not occur internationally. 
Realistically, systems of IP protection are typically taken advantage of more by domestic residents that by foreigners, even though such protection is legally available to all who might request it. The reason is probably partly a matter of information, and partly that the products that need protection are usually first sold on the producer's domestic market. Therefore I would not expect in the case of art that effect 1 would be seriously undermined in most cases.

On the other hand, as time passes and national capabilities change, one might easily find new groups of artists emerging in countries where there previously were few. These artists, as the potential beneficiaries of IP protection, may press for its adoption. I am told that the ultimate acceptance of IP protection in the Uruguay Round by developing countries who opposed it early in the negotiations was in part due to their realization that their own producers of IP were becoming significant in world markets.

ASSUMPTION 8. Demands for the products of intellectual property are the same in all countries, depending identically in all countries on prices and incomes.

This is perhaps the most critical and also the most questionable assumption of the analysis. To see why, suppose the opposite extreme case of consumers that, in each country, demand things that are different from those that are demanded by consumers in all other countries. In the case of art, suppose that each country has its own national artistic style, with no appreciation whatsoever for the styles of other countries. In such a case, IP protection is needed within a country before its art will be produced anywhere, for there would be no market for it elsewhere. Effects 1 and 2 of the above analysis disappear, because consumers would have had no interest in another country's art and would not have wanted copies of it even at marginal cost. Further, effect 3 would be correspondingly large, since IP protection in the new country would make all of that country's art viable where none of it was before.

This extreme case suggests also a more plausible middle ground where the case for limited IP protection may not be as strong as I have argued. To the extent that every country expresses its own national culture through its art, then even though consumers everywhere may enjoy the same wide variety of artistic expressions, they will also favor them in different proportions. A country that does not provide IP protection to art will put its own artists at a disadvantage, for they would not have as good a market with the consumers in other countries where IP protection is provided. As a result, the indigenous domestic art will not prosper as it would if IP protection were available at home.

One sometimes hears complaints that international trade is a negative force, undermining the cultural identities of countries who become homogenized into consumers of the same goods that are consumed in every other country. If such homogenization takes place because in fact the consumers of the world are largely identical, then it is not necessarily to be regretted. But it is also possible that con- 
sumers do have distinctive national preferences but are prevented from exercising them because a lack of IP protection saps the incentive for local producers and artists to cater to those preferences. In such cases extension of IP protection is clearly desirable.

\section{Other Considerations}

This brief review of the assumptions underlying the argument for geographic limitation on IP protection suggests that in most cases the argument does carry over from patents to art. In most cases, the assumptions appear either to be appropriate or to be violated in ways that only improve the case for limiting protection. The one exception is that just considered, of distinctive national preferences for types of art that would not be created elsewhere. It is in the interest of countries themselves, without pressure from other countries, to provide IP protection to artists who cater to those distinctive preferences.

In this concluding Section, I depart from the framework of the earlier argument and its assumptions to consider additional characteristics of art that are not well captured in that framework and that may have their own implications for the appropriate extent of IP protection.

\subsection{SCARCITY VALUE}

It is commonplace that scarcity enhances value, but for ordinary goods the reason is only that scarce supplies are allocated to those consumers who place the highest marginal value on them and are, therefore, willing to pay the highest price. For some forms of art, however, it appears that scarcity confers a value that is even greater than this. Many owners of paintings, for example, seem to value them not only for their esthetic beauty and the other pleasures that they provide to onlookers, but also for the fact that few others have similar versions of the same item. Knowing this, artists who deal in reproduced forms of their own work (prints, lithographs, etc.) make a point of numbering the copies and stating and limiting their total number. This practice makes sense only if the artists believe that their works are being valued in part for their scarcity.

If this is the case, then it adds substantially to the case for providing IP protection in art. The failure to do so undermines the artist's ability to limit supply, and this not only undermines the artist's monopoly power over price. It also lowers the value of the work to those consumers who derive satisfaction from its scarcity. Avoiding this outcome is therefore an additional benefit to extending IP protection, and also one that suggests the need to extend it to the entire world.

Of course not all art has this property that its value is enhanced by scarcity. On the contrary, much popular art seems to thrive on ubiquity, the demand picking up only when the artist or art form has become fashionable. In these cases it may be 
in the artist's own interest, up to a point, to permit copying of the work in order to get it into the public view.

\subsection{ART As A PUBLIC GOOD}

The best of art serves a greater purpose than the mere satisfaction of those individuals who happen to purchase it. Great art elevates the human spirit in a way that often transcends individuals and enriches all humanity. Also, just as the art that an individual chooses for personal display helps to define that individual, the art that a country's artists create defines the culture of that country. All of this means that the benefits from artistic creation extend well beyond the artist and the artist's customers. Art is a public good at the same time that it is a private good.

As with any public good, art is therefore under-provided by the private market. This is recognized throughout the world as governments routinely provide some subsidies to artistic creation, and various other means are also available, through non-profit organizations and other benefactors, to assist artists beyond the incentives that the private market provides. Still, subsidies to artistic endeavors are an imperfect means of providing the public good in this case, because it is difficult for such subsidies to be calibrated to the quality of the artistic product that results. It is easy for a system of subsidies to art to become subsidies only for the pretense of art, encouraging entrepreneurs rather than artists.

Therefore, there is an extra payoff to any mechanism that can further encourage art through the market. As we have seen, intellectual property rights are an imperfect means of fostering artistic creation, since they necessarily include a tradeoff between an adequate incentive for artists to create art, on the one hand, and the incentive for consumers of art to consume it, on the other. To the extent that art is a public good, this should tilt the optimal balance further toward the artists, and suggests an optimal IP regime that gives a greater share of the surplus to the artists than otherwise.Thus, this last consideration suggests a reason for further geographic extension of IP protection in art.

\section{Acknowledgements}

I have benefitted especially from conversations with John Jackson and Bob Stern regarding the economics of intellectual property rights, and from conversations with my wife, Pat Deardorff, regarding the application of these ideas to art. Partial financial support in writing this paper was provided by the Ford Foundation.

\section{References}

Deardorff, Alan V. (1990) Should patent protection be extended to all developing countries, The World Economy 13: (December), 497-507.

Deardorff, Alan V. (1992) Welfare effects of global patent protection, Economica 59: (February), 35-51. 